\title{
New Wind in Old Sails: Novel Applications of Triphos-based Transition Metal Complexes as Homogeneous Catalysts for Small Molecules and Renewables Activation
}

\author{
Irene Mellone, Federica Bertini, Luca Gonsalvi, Antonella Guerriero, and Maurizio Peruzzini*
}

Dedicated to Prof. Manfred Scheer on the occasion of his $60^{\text {th }}$ birthday.

\begin{abstract}
Recent developments in the coordination chemistry and applications of Ru-triphos [triphos = 1,1,1-tris-(diphenylphosphinomethyl)ethane] systems are reviewed, highlighting their role as active and selective homogenous catalysts for small molecule activation, biomass conversions and in carbon dioxide utilizationrelated processes.
\end{abstract}

Keywords: Biomass · Carbon dioxide utilization (CDU) · Homogeneous catalysis · Ruthenium · Triphos

\section{Introduction}

Polydentate phosphines are nowadays recognized as one of the most important classes of ligands having widespread applications in coordination chemistry. The facially coordinating tridentate ligand triphos [triphos $=1,1,1$-tris(diphenylphosphinomethyl)ethane] and its derivatives have been investigated in detail, due to their ability to yield a large variety of transition-metal complexes, many of which have found application in catalysis. [1]

Bianchini and co-workers described the use of triphos in transition-metal catalysis using platinum group metals for hydrogenation and hydroformylation of alkenes, ${ }^{[2]}$ hydrogenation of N-heterocycles, ${ }^{[3]}$ hydro-

\footnotetext{
${ }^{\star}$ Correspondence: Dr. L. Gonsalvi, Dr. M. Peruzzini Consiglio Nazionale delle Ricerche Istituto di Chimica dei Composti Organometallici (CNR-ICCOM)

Via Madonna del Piano 10, 50019 Sesto Fiorentino (Firenze), Italy

E-mail: I.gonsalvi@iccom.cnr.it

maurizio.peruzzini@iccom.cnr.it
}

genation, hydrogenolysis, hydrodesulfurization of thiophene, ${ }^{[4]}$ and oxidation of catechols. ${ }^{[5]}$

In particular, the reactivity of ruthenium(II)-triphos complexes toward various substrates in hydrogenation reactions ${ }^{[6,7]}$ were studied extensively by NMR and IR spectroscopies. ${ }^{[8]}$ The increased stability provided by the tripodal nature of the triphos ligand promotes the highly active catalyst formation for the hydrogenation of esters, amides, and even free carboxylic acids. ${ }^{[9]}$

Elsevier and co-workers reported in 1997 the hydrogenation of activated esters using in situ formed catalysts obtained from ruthenium precursors such as $\left[\mathrm{Ru}(\mathrm{acac})_{3}\right]$ and triphos. ${ }^{[9 \mathrm{~d}, \mathrm{e}]}$

Since then, several research groups have investigated the mechanism of hydrogenation in an attempt to explain the role of the hydride complex in these reactions. Frediani and co-workers studied the mechanism of hydrogenation of esters and lactones by a deuterium labeling study. ${ }^{[9 \mathrm{~g}]}$ Chaplin and Dyson proposed a mechanism for the hydrogenation of alkenes using a $\mathrm{Ru}$ /triphos complex involving non-classical hydrides. ${ }^{[10]}$

In recent years the use of rutheniumtriphos catalytic systems, both as welldefined complexes and as in situ combinations of metal precursors and ligand have been employed in new and old reactions such as the catalytic conversion of biomass ${ }^{[11]}$ and $\mathrm{CO}_{2}$ utilization for the production of fuels and chemicals. [12]

\section{Selective Catalytic Conversions of Biomass Feedstocks to Useful Chemicals}

In view of the changing world energy demands, biomass could potentially become an important resource for the production of biofuels, bioenergy and biomaterials. Feedstocks derived from biomass are generally subdivided in three classes: starchy feedstocks, triglyceride feedstocks, and lignocellulose. The latter is the most abundant class of biomass and its carbohydrates can be used to produce building block chemicals via biological or chemical means, which in turn can be used to obtain a number of high-value products. Usually, the main target for building block chemicals is the presence of functional groups that can be transformed into new useful molecules. [13]

The development of new synthetic methods and highly specific catalysts is therefore required for the functionalization of bio-substrates to obtain a broad range of chemical compounds in a sustainable way.

Among the building blocks that can be produced from sugars, levulinic acid (LA) and itaconic acid (IA) possess a central importance within the biorefinery. ${ }^{[13 \mathrm{~d}]}$ Levulinic acid has frequently been used for its conversion to $\gamma$-valerolactone (GVL), a cyclic ester considered as one of the key components in the biorefinery. A further conversion of LA can be undertaken to obtain biogenic diols, such as 1,4-PDO, and the cyclic ether 2-methyltetrahydrofuran 
(2-MTHF) useful as monomer for biodegradable polymeric materials and as an alternative solvent in the pharmaceutical industry, respectively (Scheme 1). Itaconic acid is also an important feedstock and its reactivity is reminiscent of maleic acid and maleic anhydride, still obtained from petrochemical sources.

Recently, Leitner and co-workers reported the use of the multifunctional catalyst system composed of the ruthenium precursor $\mathrm{Ru}(\mathrm{acac})_{3}$ and triphos with ionic and/or acidic additives for selective conversions of levulinic acid (LA, Scheme 2) and itaconic acid (IA, Scheme 3) to lactones, diols and cyclic esters via hydrogenationdehydration sequences. ${ }^{[14,15]}$

In the latter publication, it was shown that a fundamental role was played by the combination of the stereoelectronic properties of the ligand, the effect of ionic additives on the reactivity and stability of the active species, the strength of the acidic additive, reaction temperature and pressure. In the presence of a $\mathrm{Ru}(\mathrm{acac})_{3}$ :triphos ratio of 1:2, LA and IA were converted into the desired products with over $90 \%$ yields, at 160 and $195{ }^{\circ} \mathrm{C}$ respectively, under a hydrogen pressure of 100 bar with control of the dehydration process due to the acidity of the reaction medium (Schemes 2 and 3). ${ }^{[14]}$

Leitner and co-workers also reported a combined theoretical and experimental study to explain the mechanism of this system. ${ }^{[15]}$ All obtained results suggest that the complex fragment [RuH(triphos) $]^{+}$represents the catalytically active species for the reduction of the $\mathrm{C}=\mathrm{O}$ functionality in aldehydes, ketones, lactones, and even free carboxylic acids. DFT calculations suggest that the reaction involves a hydride transfer from $\mathrm{Ru}-\mathrm{H}$ onto the carbonyl or carboxyl carbon followed by protonation of the resulting $\mathrm{Ru}-\mathrm{O}$ unit via $\sigma$-bond metathesis from a coordinated dihydrogen molecule, regenerating the catalytically active $\mathrm{Ru}-\mathrm{H}$ species.

A significant step forward in the synthetic chemistry of Ru-triphos complexes was described by Leitner and co-workers, reporting the novel $\left[\mathrm{Ru}\left(\mathrm{P}_{3}\right)(\mathrm{TMM})\right]$ complex $(\mathrm{TMM}=$ trimethylenemethane $)$, synthesized from [Ru(cod)(methallyl) $\left(\operatorname{cod}=1,5\right.$-cyclooctadiene, methallyl $=\eta^{3}$ $\mathrm{C}_{4} \mathrm{H}_{7}$ ) and tripodal phosphine ligands $\mathrm{P}_{3}$ (Scheme 4). These complexes were found to be active catalysts for hydrogen transfer reactions and $\mathrm{C}=\mathrm{O}$ cleavage of $\beta-[\mathrm{O}]-4^{\prime}-$ glycerolarylether linkages of lignin. ${ }^{[16]}$

The experiments were carried out using 2-phenoxy-1-phenylethanol as the model compound for lignin linkages and comparing the activity of catalyst bearing mono $\left(\mathrm{PPh}_{3}\right)$ and bidentate phosphines (dppe) and (9,9-dimethyl-9H-xanthene-4,5-diyl) bis(diphenylphosphine) (A) to the tri-

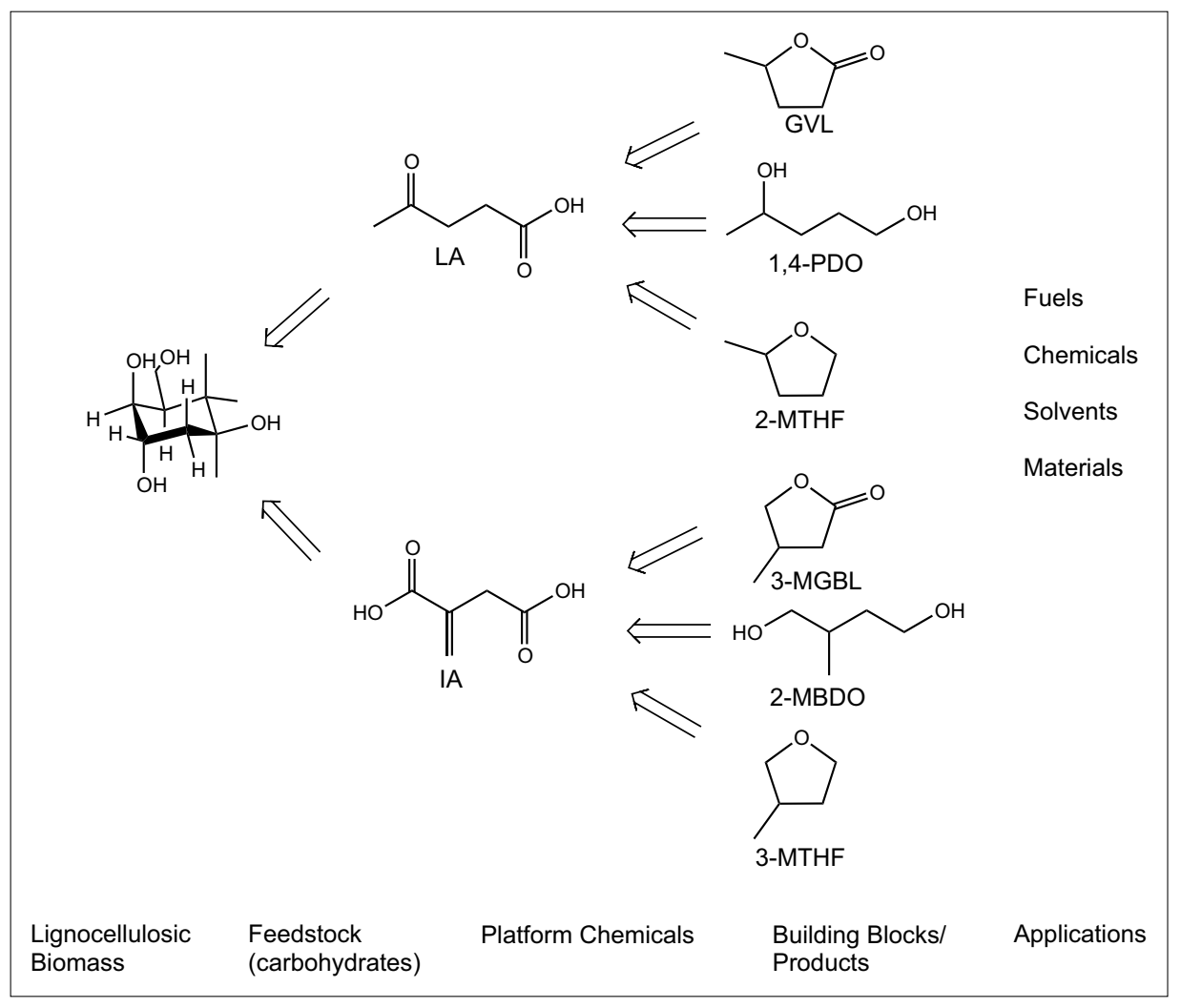

Scheme 1. Use of LA and IA to fuels, chemicals, solvents, etc. ${ }^{[14]}$

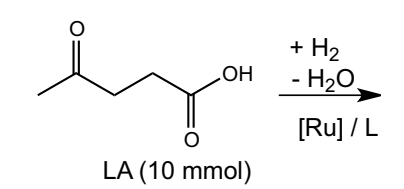

$\mathrm{Ru}(\mathrm{acac})_{3}(0.1 \%) ; \mathrm{NH}_{4} \mathrm{PF}_{6}(1.0 \%)$; $\mathrm{pH}_{2}=10$ bar; $18 \mathrm{~h}$

$\mathrm{L}=\mathrm{P}(\text { nOct })_{3}(1.0 \%) ; \mathrm{T}=160{ }^{\circ} \mathrm{C}$

$\mathrm{L}=\mathrm{dppb}(0.13 \%) ; \mathrm{T}=160^{\circ} \mathrm{C}$

$\mathrm{L}=\operatorname{dppb}(0.13 \%) ; \mathrm{T}=200^{\circ} \mathrm{C}$

$\mathrm{L}=$ triphos $(0.2 \%) ; \mathrm{T}=160^{\circ} \mathrm{C}$. no additive

$\mathrm{L}=\operatorname{triphos}(0.2 \%) ; \mathrm{T}=160^{\circ} \mathrm{C}$ $\mathrm{NH}_{4} \mathrm{PF}_{6}(1.0 \%)$

$\mathrm{L}=\operatorname{triphos}(0.2 \%) ; \mathrm{T}=160^{\circ} \mathrm{C}$ $\mathrm{pTsOH}(1.0 \%)$

$\mathrm{L}=$ triphos $(0.2 \%) ; \mathrm{T}=160{ }^{\circ} \mathrm{C}$ $\mathrm{alL}+\mathrm{NH}_{4} \mathrm{PF}_{6}(1.0 \%)$

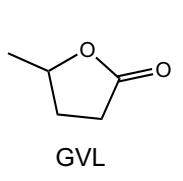

$99 \%$

$89 \%$

$39 \%$

$3 \%$

$8 \%$

$58 \%$

$1 \%$<smiles>CC(O)CCCO</smiles>
$\stackrel{-\mathrm{H}_{2} \mathrm{O}}{\longrightarrow}$<smiles>[R4][X]F</smiles>

2-MTHF

$0 \%$

$0 \%$

$0 \%$

$51 \%$

$51 \%$

$53 \%$

$39 \%$

$92 \%$
Scheme 2. Hydrogenation-dehydration pathways for the conversion of LA to chemicals. [15]

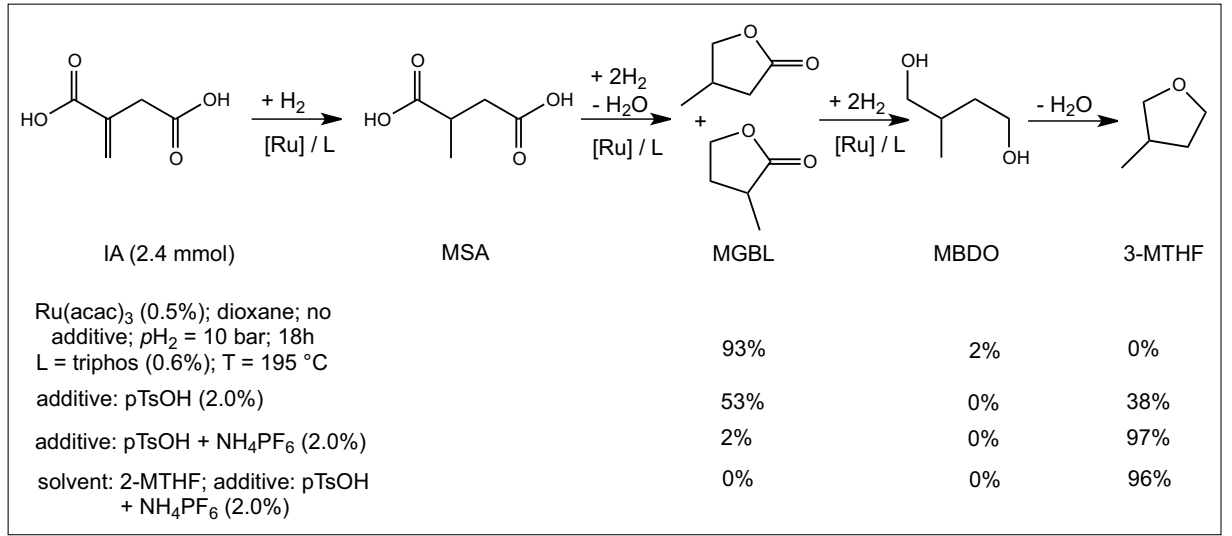

Scheme 3. Hydrogenation-dehydration pathways for the conversion of IA to chemicals. ${ }^{15]}$ 
podal phosphines 1,1,1-tris(diphenylph osphinomethyl)ethane (triphos-B), and bis(diphenylphosphinoethyl)phenylphosphine (triphos-C). (Scheme 5).

The catalysts formed in situ from $\left[\mathrm{Ru}(\mathrm{cod})\left(\right.\right.$ methallyl) $\left.{ }_{2}\right] /$ triphosphines showed an enhanced activity and the best result was obtained with complex [Ru(triphos-C)(TMM)], synthesized and characterized by X-ray analysis. With complex [Ru(triphos-C)(TMM)] at $135{ }^{\circ} \mathrm{C}$, yields of over $90 \%$ of phenol and acetophenone were achieved after only $2 \mathrm{~h}$ (Scheme 6). The complexes [Ru(triphos-B)(TMM)] and [Ru(triphos-C) (TMM)] were also characterized in the solid state by single crystal X-ray diffraction (Fig. 1).

More recently, Beller and co-workers investigated the conversion of LA to GVL using ruthenium-triphos based systems as efficient catalysts at $140{ }^{\circ} \mathrm{C}$ under solventfree conditions. ${ }^{[17]}$

Initially, methyl levulinate was used as the model substrate and the reaction was performed in the presence of $\mathrm{Ru}(\mathrm{acac})_{3}$ as metal precursor and $p$-toluenesulfonic acid (PTSA) as an additive in catalytic amounts, obtaining low yields of GVL. Therefore, various phosphines (Scheme 7) were added to the reaction mixtures and three different triphos analogues (L3, L4, L6) have demonstrated high efficiency, especially L6, leading to the highest yields $(95 \%)$, catalyst turnover numbers $($ TON $=$ 75855) and catalyst turnover frequencies $\left(\mathrm{TOF}=1382 \mathrm{~h}^{-1}\right)$.

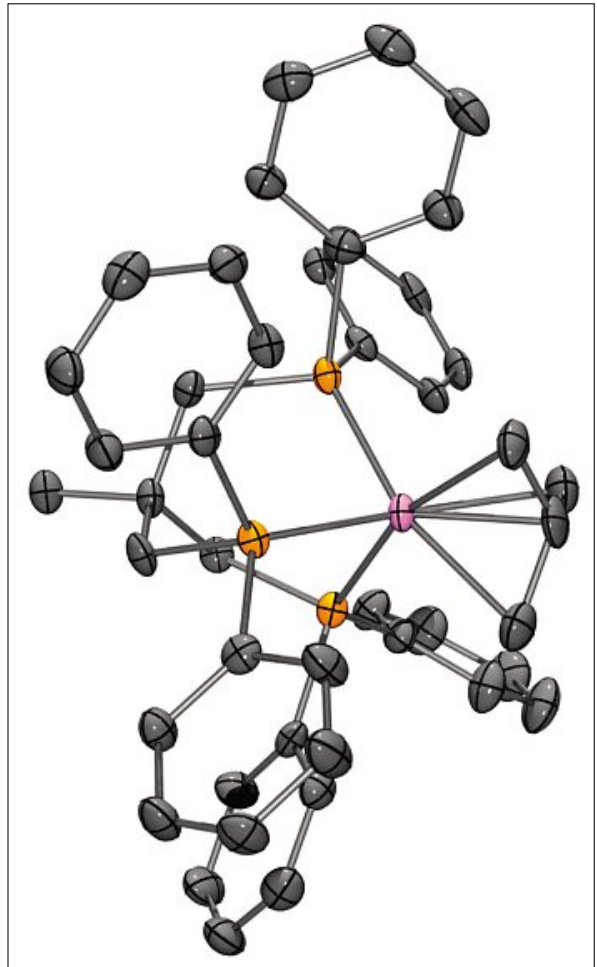

Fig. 1. X-ray crystal structure of complex [Ru(triphos)(TMM)] (TMM = trimethylenemethane). [16]

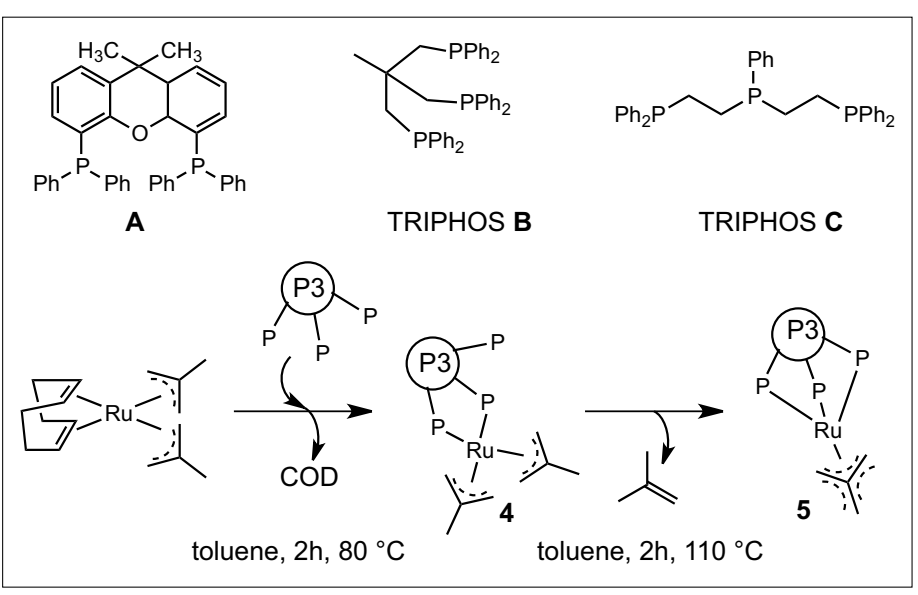

Scheme 4. Formation of complexes $\left[\mathrm{Ru}\left(\mathrm{P}_{3}\right)\right.$ (TMM)] starting from $\left[\mathrm{Ru}(\mathrm{cod})(\text { methylallyl) })_{2}\right]$ and the tridentate phosphines $\mathrm{P}_{3}=\mathrm{B}$ C.[16]

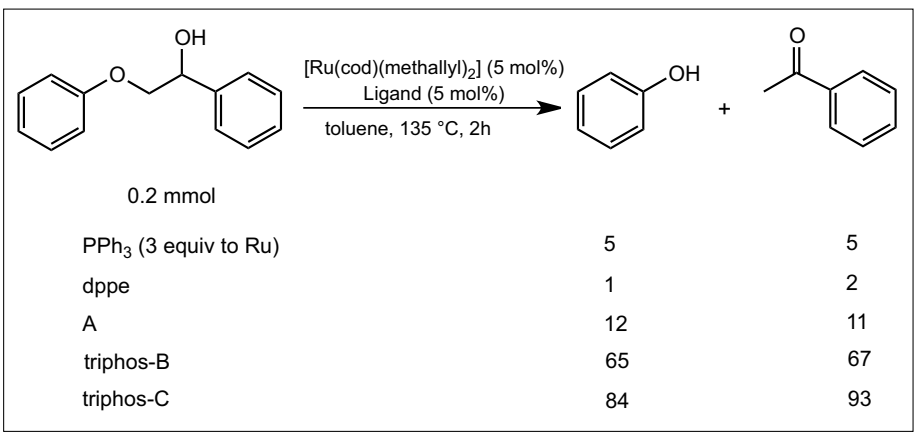

Scheme 5. Cleavage of 2-phenoxy1-phenylethanol using $[\mathrm{Ru}(\mathrm{cod})$ (methal$\left.|y|)_{2}\right]$ and phosphine ligands. ${ }^{[16]}$

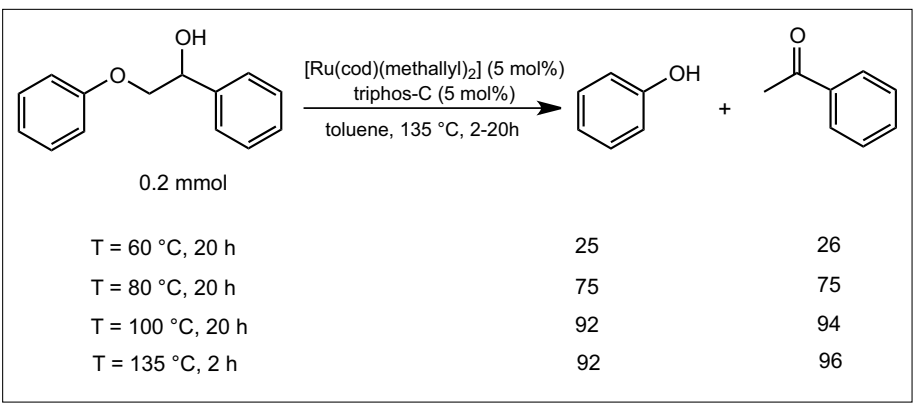

Scheme 6.

Temperature effect on the catalytic cleavage of 2-phenoxy1-phenylethanol using $\left[\mathrm{Ru}(\mathrm{cod})\left(\right.\right.$ methyally) $\left.{ }_{2}\right]$ and triphos-C. ${ }^{[16]}$

\section{Production of Chemicals and Fuels from Small Molecule Activation}

Other applications of the ruthenium/ triphos catalytic system were found in the activation of small molecules such as $\mathrm{CO}_{2}$ and $\mathrm{H}_{2}$, and in the reduction of unsaturated functional groups in more complex organic substrates to obtain important classes of compounds both in bulk chemistry and as high-value intermediates in organic synthesis.

Amines, an important class of compounds finding application in many industrial processes, ${ }^{[18]}$ can in principle be obtained from the hydrogenation of amides with molecular hydrogen, allowing for their more sustainable production in the pharmaceutical industry. ${ }^{[19]}$ In the past, this reaction was reported using ruthenium/triphos but a mixture of products was obtained without formation of the desired primary amines. ${ }^{[20]}$

Cole-Hamilton and co-workers proposed the use of the same system but in the presence of water and ammonia, fundamental requirements for the stabilization of the catalyst and for the selective primary amine formation, respectively. ${ }^{[9 f]}$ The best results were obtained using $\left[\mathrm{Ru}(\mathrm{acac})_{3}\right]$ and triphos in the presence of liquid ammonia with a conversion of $100 \%$ and a selectivity to primary amine of $44 \%$. The selectivity was increased to $85 \%$ using aqueous ammonia. A mechanism was proposed for this reaction (Scheme 8).

More recently, the same authors reported on the hydrogenation of amides to primary, secondary and tertiary amines with high selectivity in the presence of $\left[\mathrm{Ru}(\mathrm{acac})_{3}\right]$, triphos and methanesulfonic acid (MSA). With this catalytic system, the hydrogenation of amides to amines in the presence of aromatic rings was also performed without cleavage of the $\mathrm{C}-\mathrm{N}$ bond, which is the principle cause of the alcohols and other byproducts formation (Scheme 9). [21]

At hydrogen pressure of $10 \mathrm{bar}$ and temperature around $200-210{ }^{\circ} \mathrm{C}$, the cata- 

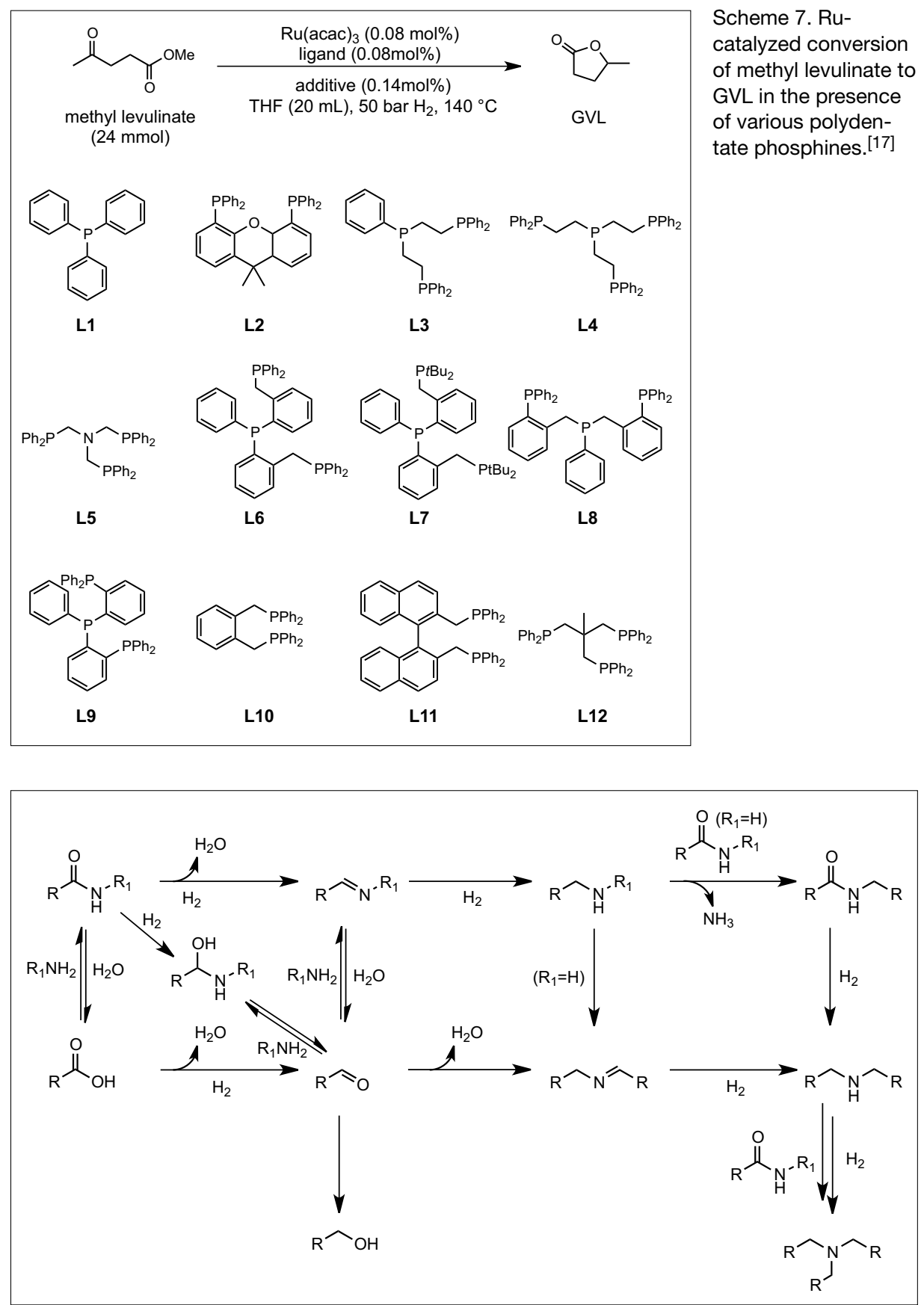

Scheme 8. Proposed Ru-triphos catalyzed amide hydrogenation mechanism. [8f]

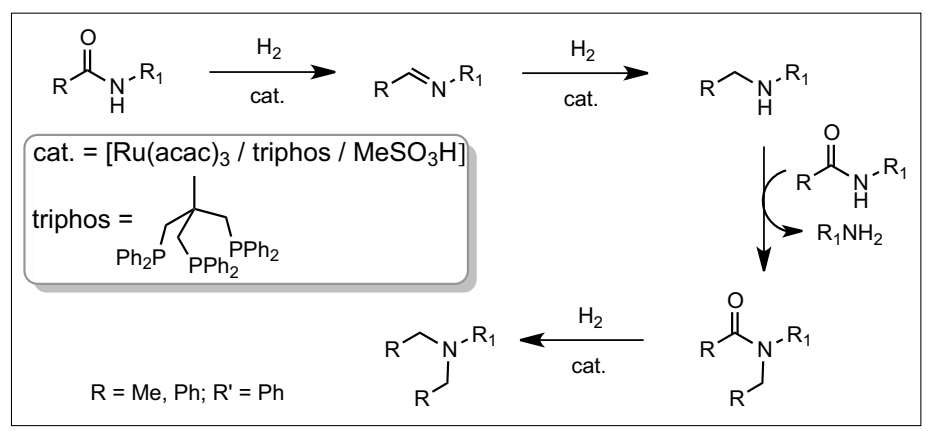

Scheme 9. Products observed during the catalytic hydrogenation of amides to amines.[21]

lytic system brought about successfully the hydrogenation of a wide range of amides. The best results were obtained for benzanilide and $N$-phenylacetamide with a conversion of $100 \%$ and selectivity up to $90 \%$. catalyzed conversion of methyl levulinate to GVL in the presence of various polydentate phosphines. [17]
The role of the so-formed mixture of $\mathrm{Ru}$ triphos-MSA complexes would act as reservoir for the $\left[\mathrm{Ru}(\text { triphos) }]^{2+}\right.$ fragment, identified as the active catalytic species, and tune the protonation-deprotonation steps necessary for efficient catalyst turnover. ${ }^{[21]}$

The complex [Ru(triphos)(TMM)] found various applications as an efficient homogeneous catalyst, beyond the $\mathrm{C}=\mathrm{O}$ bond cleavage in lignin model compounds discussed above, ${ }^{[17]}$ it was tested for the hydrogenation of formate esters and $\mathrm{CO}_{2}$ hydrogenation to methanol.

Leitner and co-workers demonstrated that this system is a useful catalyst for the hydrogenation of a wide range of challenging functionalities such as carboxylic esters, amides, carboxylic acids, carbonates, and urea derivatives. ${ }^{[22]}$ From the combination of multinuclear NMR spectroscopic studies and DFT calculations, it was shown that the active species is the $[\mathrm{Ru}$ (triphos)(solv) $\mathrm{H}_{2}$ ] complex (solv = THF, $\left.\mathrm{CH}_{3} \mathrm{CN}\right)$ obtained by reaction of [Ru(triphos)(TMM)] with $\mathrm{H}_{2}$ either under neutral conditions or in the presence of catalytic amounts of an acid such as methansulfonic acid (MSA) or $\mathrm{HNTf}_{2}$ (bis-trifluoromethane sulfonamide) as additive. ${ }^{[22]}$

DFT calculations demonstrated together with experimental results that the use of complex [Ru(triphos)(TMM)] as hydrogenation precatalyst without further additives enables the selective reduction of $\mathrm{C}=\mathrm{O}$ bonds in carboxylic esters, acids, anhydrides, and selected amides (Scheme 10). By adding an acidic co-catalyst such as $\mathrm{HNTf}_{2}$ to the reaction mixture under hydrogen pressure $\left(p \mathrm{H}_{2}=50 \mathrm{bar}\right)$, the cationic species $\left[\mathrm{Ru}(\text { triphos })(\text { Solvent })(\mathrm{H})\left(\eta^{2}-\mathrm{H}_{2}\right)\right]^{+}$ is formed instead, a selective catalyst for the reduction of primary amides, ureas, and carbonates with excellent yields. The presence of a co-catalyst is needed to avoid the formation of the catalytically inactive complex $\left[\mathrm{Ru}(\right.$ triphos $\left.)(\mathrm{CO})(\mathrm{H})_{2}\right]$, a thermodynamic sink connected to catalyst deactivation pathway.

Another important class of molecules are methyl-substituted amines, a class of bioactive compounds utilized as intermediates for chemical syntheses. ${ }^{[23]}$ Novel protocols for sustainable amine methylation methods are very attractive. Currently, the industrial method for methylation of amines uses toxic solvents and methylation reagents such as MeI, MeOTf etc. ${ }^{[24]}$ In the past years, several research groups have focused their attention on catalytic methylations using $\mathrm{CO}_{2}$ and $\mathrm{H}_{2}$, a sustainable method with $\mathrm{H}_{2} \mathrm{O}$ as the only by-product (Scheme 11).

Beller and co-workers reported the use of the $\mathrm{CO} / \mathrm{H}_{2}$ mixture as the methylation reagent using $\left[\mathrm{Ru}(\mathrm{acac})_{3}\right]$ and triphos in the presence of a catalytic amount of a 
Brønsted acid as the most active protocol for the methylation of both aromatic and aliphatic amines.[25] Under these conditions, a reaction pathway was proposed that proceeds via formamide and methanol intermediates (Scheme 12).

Leitner and coworkers studied the chemoselectivity of [Ru(triphos)(TMM)] catalyst in coupling reactions of primary amines, aldehydes and $\mathrm{CO}_{2}$ to produce tertiary $\mathrm{N}$-methyl amines in one step ${ }^{[26]}$ (Scheme 13).

Initially, the reaction conditions were optimized starting with the methylation of imines in the presence of $\mathrm{HNTf}_{2}$ as co-catalyst. As shown in Scheme 14, an increase of temperature and reaction time favored the formation of the methylation $v s$. the hydrogenation product.

The enhanced selectivity is due to the use of non-coordinating anion $\mathrm{HNTf}_{2}$, differently from MSA. After investigating a set of different isolated imines, the reaction was carried out coupling directly primary amines, aldehydes, and $\mathrm{CO}_{2}$. Also in this case, a range of unsymmetrical tertiary amines were synthesized in excellent yields. ${ }^{[26]}$ Finally, the reductive methylation of the imine group in $N$-methyl amine for the synthesis of butenafine, an antifungal agent, was carried out to test the scope of this method in a commercially relevant process (Scheme 15).

Cantat and co-workers recently reported the use of formic acid (FA) as carbon and hydrogen source for methylation of amines, expanding on their previous reports on this kind of reaction using hydrosilanes as sacrificial reductants. The reactions were carried out at $150{ }^{\circ} \mathrm{C}$ using a combination of [Ru(COD)(methylallyl ${ }_{2}$ ] precursor and triphos as catalyst, in the presence of $\mathrm{HCOOH}$ and MSA, achieving a good conversion of aniline to $\mathrm{N}$-methylaniline (major product) and $N, N$ dimethylaniline. ${ }^{[27]}$

Increasing the $\mathrm{HCOOH}$ loading up to an optimal value of 6 equivalents, the formation of $\mathrm{N}-\mathrm{CH}_{3}$ derivatives was favored and the yields of $N$-methylaniline and $N, N$ dimethylaniline increased. The presence of an acid co-catalyst is crucial to guarantee the catalytic activity. In particular, for the methylation of secondary amines HNTf was found to be the most efficient additive (Scheme 16).

However, the limits of the methylation reaction with $\mathrm{HCOOH}$ emerged from the study with a wide variety of amines, complemented by DFT calculations.[27] The $\mathrm{N}-\mathrm{CH}_{3}$ group formation proceeds via formylation/transfer hydrogenation with metal hydride intermediate as rate determining step, occurring under thermodynamic control.

$\mathrm{Ru} /$ triphos catalytic systems involving $\mathrm{CO}_{2}$ and $\mathrm{H}_{2}$ activation have also been used

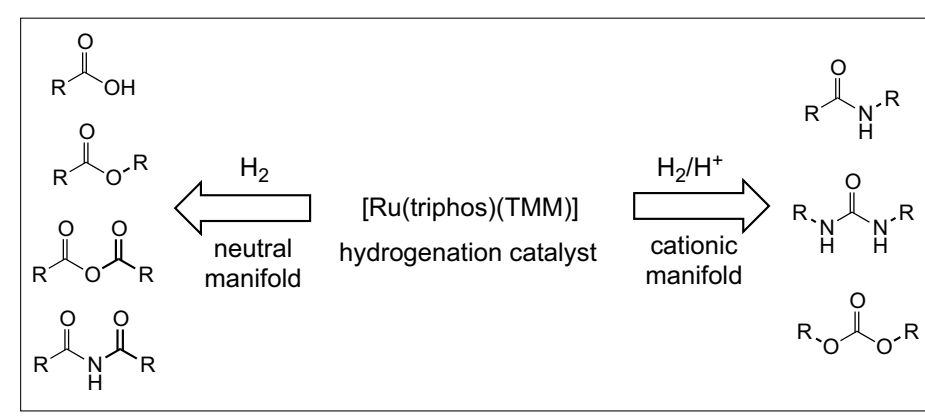

Scheme 10. The range of challenging functionalities that can be hydrogenated by

[Ru(triphos)(TMM)]. [22]

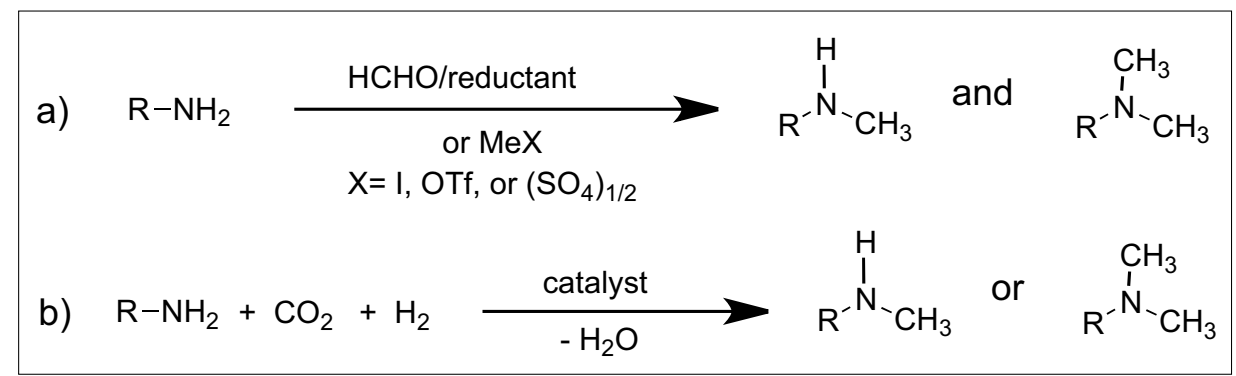

Scheme 11. Established pathway (a) and novel approach (b) to amine methylation using $\mathrm{CO}_{2}, \mathrm{H}_{2}$ and a Ru-triphos catalyst.[25]

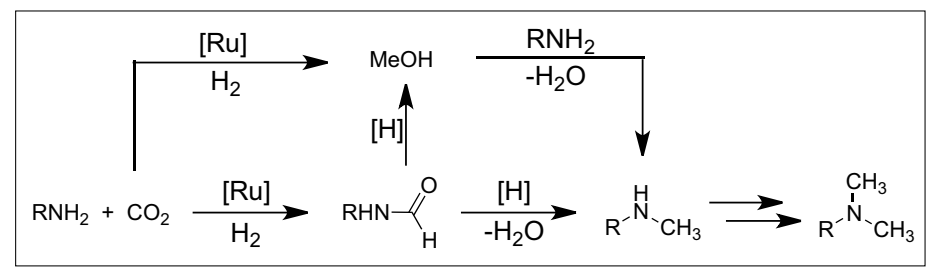

Scheme 12

Proposed steps in amines methylation using $\mathrm{CO}_{2} \cdot{ }^{[25]}$

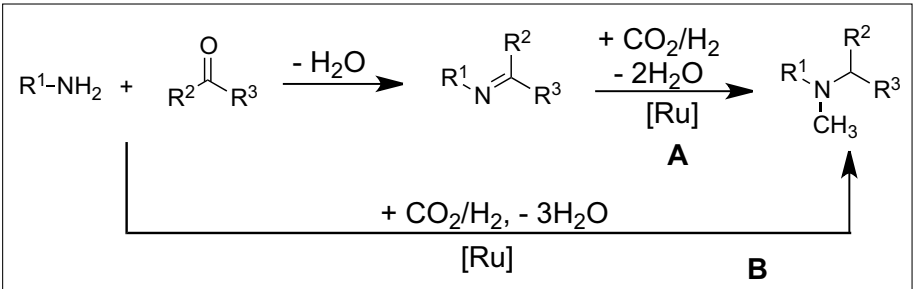

Scheme 13.

Reductive methylation of imines with $\mathrm{CO}_{2}$ and $\mathrm{H}_{2}$ (path $\mathrm{A}$ ), and $N$-methyl amines one-step reaction from primary amines, aldehydes and $\mathrm{CO}_{2}$ (path B). [26]

$[R u]=[R u($ triphos $)(T M M)]$

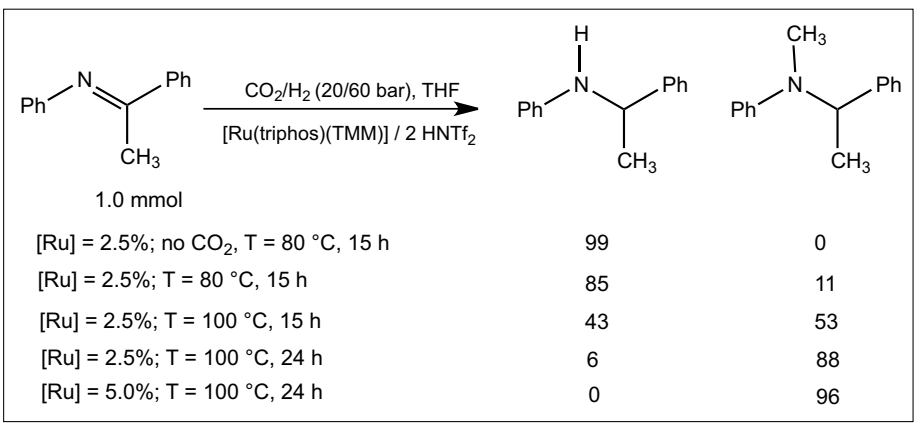

Scheme 14. Reductive imine methylation with $\mathrm{CO}_{2}$ and $\mathrm{H}_{2}$ using [Ru(triphos)(TMM)] and HNTF $_{2}$. [26]

for the direct synthesis of formic acid and formate or methanol. These simple organic molecules are rich in hydrogen content and can in turn be used as Liquid Organic Hydride Carriers (LOHC) to generate $\mathrm{H}_{2}$ by catalytic dehydrogenation reactions.

Recently, our group investigated the $\mathrm{HCOOH}$ dehydrogenation reaction using both the $\mathrm{Ru}(\mathrm{acac})_{3}$ /triphos in situ system and the isolated complex [Ru(triphos) $\left.(\mathrm{MeCN})_{3}\right](\mathrm{OTf})_{2}$ as promising homogeneous catalysts for this reaction. ${ }^{[28]}$ In particular, $\left[\mathrm{Ru}\right.$ (triphos) $\left.(\mathrm{MeCN})_{3}\right](\mathrm{OTf})_{2}$ showed superior performances with a TON of 10000 after $6 \mathrm{~h}$ using $0.01 \mathrm{~mol} \%$ of the catalyst and allowed for recycling up to eight times ( $0.1 \mathrm{~mol} \%$ catalyst) giving a total TON of 8000 after $c a$. 14 h of con- 


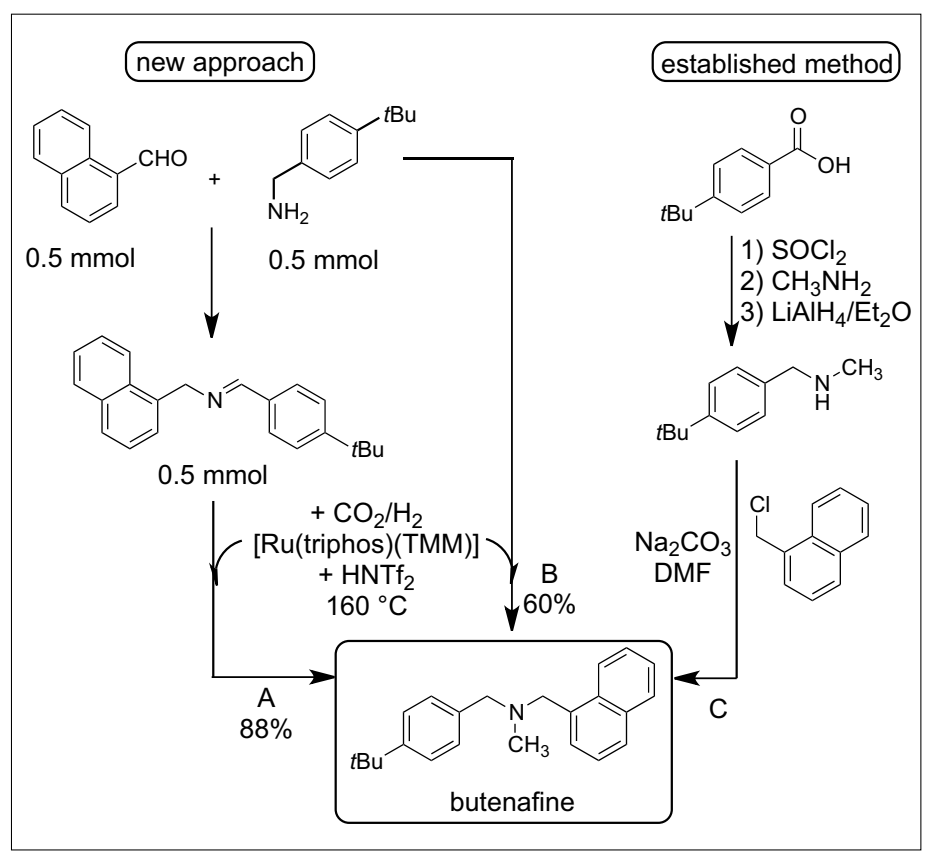

Scheme 15.

Synthesis of butenafine by novel (A, $B)$ and established methods $(\mathrm{C}) .{ }^{[26}$ ]

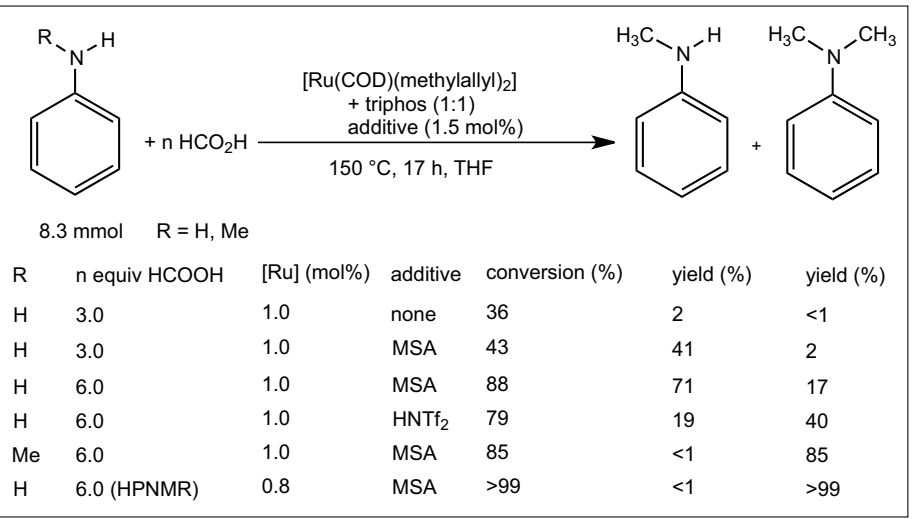

Scheme 16. Rucatalyzed methylation of aniline and methylaniline with $\mathrm{HCOOH} .[27]$

tinuous reaction at $80{ }^{\circ} \mathrm{C}$ in the presence of OctNMe (Fig. 2).

Mechanistic details on the reactivity of complex $[\mathrm{Ru} \text { (triphos)(MeCN) })_{3}$ (OTf) with formate and formic acid/amine were obtained by a combination of variable temperature (VT) NMR experiments and DFT calculations. ${ }^{[29]}$ It was shown that ligand substitution led to precatalyst activation giving a bis-formate complex [Ru(triphos) $\left.\left(\eta^{2}-\mathrm{O}_{2} \mathrm{CH}\right)\left(\eta^{1}-\mathrm{O}_{2} \mathrm{CH}\right)\right]$ which then proceeds to release $\mathrm{H}_{2}$ and $\mathrm{CO}_{2}$.

Cantat and coworkers reported the efficient synthesis of methanol by direct disproportionation of formic acid using $[\mathrm{Ru}$ (triphos)(TMM)] as catalyst. The reaction was carried out in THF at $150{ }^{\circ} \mathrm{C}$ in the presence of methanesulfonic acid (MSA) reaching methanol yields of up to $50.2 \% .{ }^{[30]}$

A combination of NMR studies and DFT calculations was carried out to investigate the competition between the dehydrogenation of formic acid and its disproportionation to $\mathrm{MeOH}$. DFT calculations highlighted the central role of the hydride complex $\left[\mathrm{Ru}\left(\kappa^{3}-\right.\right.$ triphos $\left.\left.^{\mathrm{Me}}\right)(\mathrm{H})\left(\eta^{2}-\mathrm{O}_{2} \mathrm{CH}\right)\right]$ derived from $\left[\mathrm{Ru}\left(\kappa^{3}\right.\right.$-triphos $\left.{ }^{\mathrm{Me}}\right)\left(\eta^{1}-\mathrm{O}_{2} \mathrm{CH}\right)$
$\left.\left(\eta^{2}-\mathrm{O}_{2} \mathrm{CH}\right)\right]$ by $\mathrm{CO}_{2}$ elimination and hydride transfer (triphos ${ }^{\mathrm{Me}}=$ simplified triphos model, Me instead of $\mathrm{Ph}$ groups on $\mathrm{P}$ atoms), representing the rate-determining step of the reaction. Coordination of FA Chemistry. followed along different pathways, leading to dehydrogenation $v s$. disproportionation (Scheme 17).

Methanol[31] can also be obtained by steering the selectivity of $\mathrm{CO}_{2}$ hydrogenation with suitable catalysts and reaction conditions. Such a process would represent an important example of CDU (carbon dioxide utilization) and allow for the sustainable use of waste greenhouse gas into a valuable feedstock. ${ }^{[32]}$ Leitner showed that both the in situ generated $\mathrm{Ru}(\mathrm{acac})_{3} /$ triphos system and the ruthenium complex $[\mathrm{Ru}($ triphos)(TMM)] are active in the homogeneous hydrogenation of $\mathrm{CO}_{2}$ to methanol, at $140{ }^{\circ} \mathrm{C}$ under a total $\mathrm{CO}_{2} / \mathrm{H}_{2}(1: 3)$ pressure of 80 bar under acidic conditions (Scheme 18). [33]

Mechanistic studies obtained from NMR experiments and DFT calculations demonstrated that the cationic formate complex $\left[\mathrm{Ru}(\text { triphos })\left(\eta^{2}-\mathrm{O}_{2} \mathrm{CH}\right)(\text { solv })\right]^{+}$ (solv $=\mathrm{THF}, \mathrm{CH}_{3} \mathrm{CN}$ ) is the catalytically active species, identified by ${ }^{31} \mathrm{P}$ NMR signals at $44.2 \mathrm{ppm}$ (room temperature, $d_{8}-$ THF) that split into a doublet $(46.3 \mathrm{ppm}$, $\left.2 \mathrm{P},{ }^{2} J_{\mathrm{Pp}}=42.5 \mathrm{~Hz}\right)$ and a triplet $(43.9$ ppm, $1 \mathrm{P},{ }^{2} J_{\mathrm{PP}}=42.5 \mathrm{~Hz}$ ) at $233 \mathrm{~K}$, further confirmed by $\left[{ }^{1} \mathrm{H},{ }^{31} \mathrm{P}\right]-\mathrm{HMBC}-\mathrm{NMR}$ and $\left[{ }^{1} \mathrm{H},{ }^{13} \mathrm{C}\right]$-HMBC-NMR spectra showing a broad singlet at $8.7 \mathrm{ppm}$ and a singlet at $178.8 \mathrm{ppm}$, respectively.

DFT calculations were used to explore the mechanism of $\mathrm{CO}_{2}$ hydrogenation to methanol via the formate complex $\left[\mathrm{Ru}(\text { triphos })\left(\eta^{2}-\mathrm{O}_{2} \mathrm{CH}\right)(\text { solv })\right]^{+}$and a catalytic cycle was proposed (Scheme 19).

Furthermore, the catalyst could be recycled in a biphasic system 2-MTHF/ $\mathrm{H}_{2} \mathrm{O}$ where it was retained in the organic phase while $\mathrm{MeOH}$ was extracted within the aqueous phase, opening the possibility for continuous-flow system (Scheme 20).

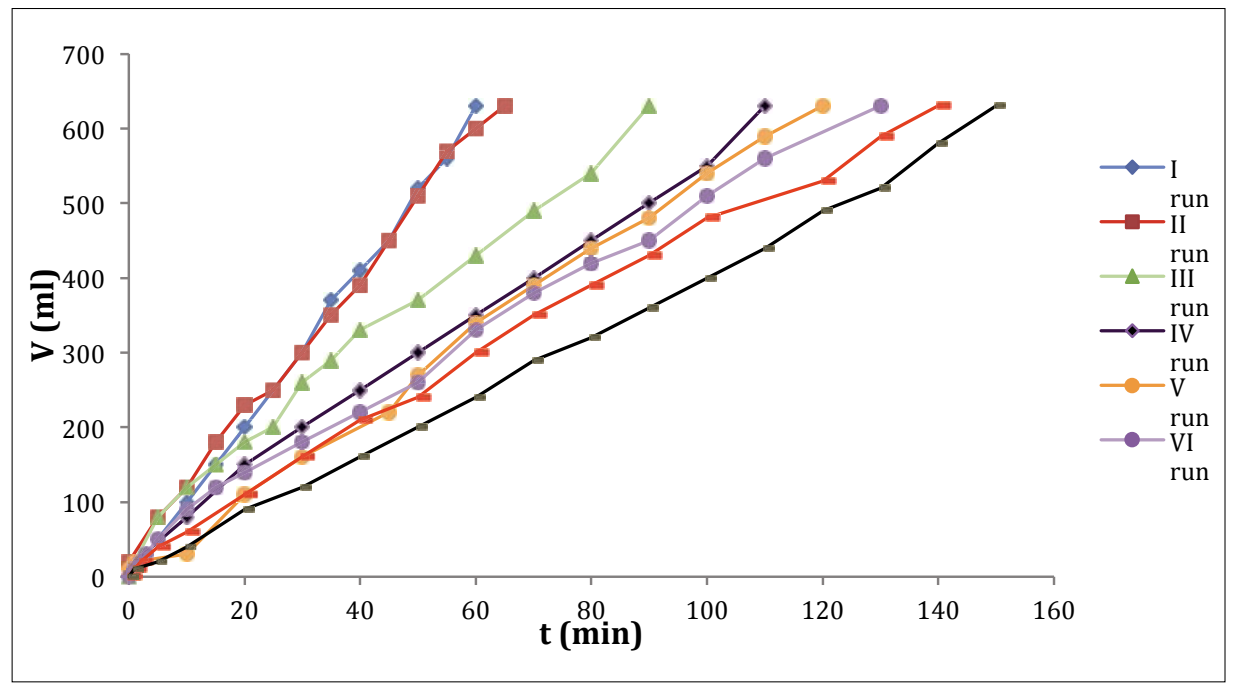

Fig. 2. Catalyst recycling for $\mathrm{HCOOH}$ dehydrogenation reactions in the presence of $[\mathrm{Ru}$ (triphos) $(\mathrm{MeCN})_{3}(\mathrm{OTf})_{2}$ (for conditions see ref. [28]). Reproduced by permission of The Royal Society of 


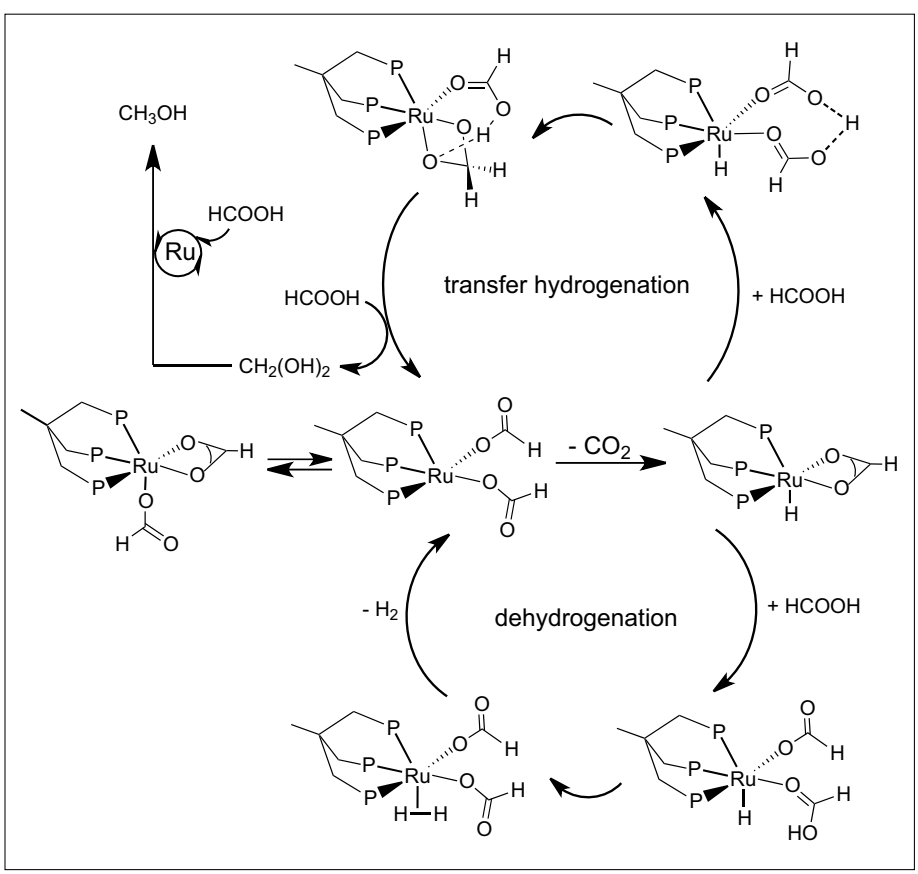

Scheme 17

Mechanisms for competing $\mathrm{HCOOH}$ disproportionation vs dehydrogenation in the presence of $\left[\mathrm{Ru}\right.$ (triphos) $\left(\eta^{1}-\mathrm{O}_{2} \mathrm{CH}\right)$ $\left.\left(\eta^{2}-\mathrm{O}_{2} \mathrm{CH}\right)\right]$. [30]

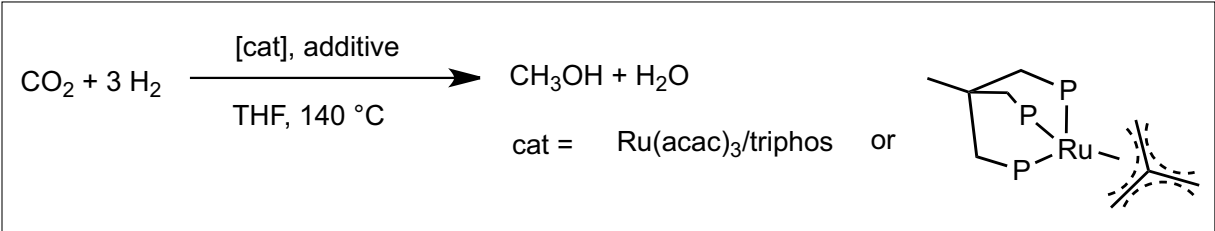

Scheme 18. Homogeneous hydrogenation of $\mathrm{CO}_{2}$ to $\mathrm{MeOH}$ catalyzed by in situ generated $\mathrm{Ru}(\mathrm{acac})_{3} /$ triphos system and the ruthenium complex [Ru(triphos)(TMM)] under acidic conditions.

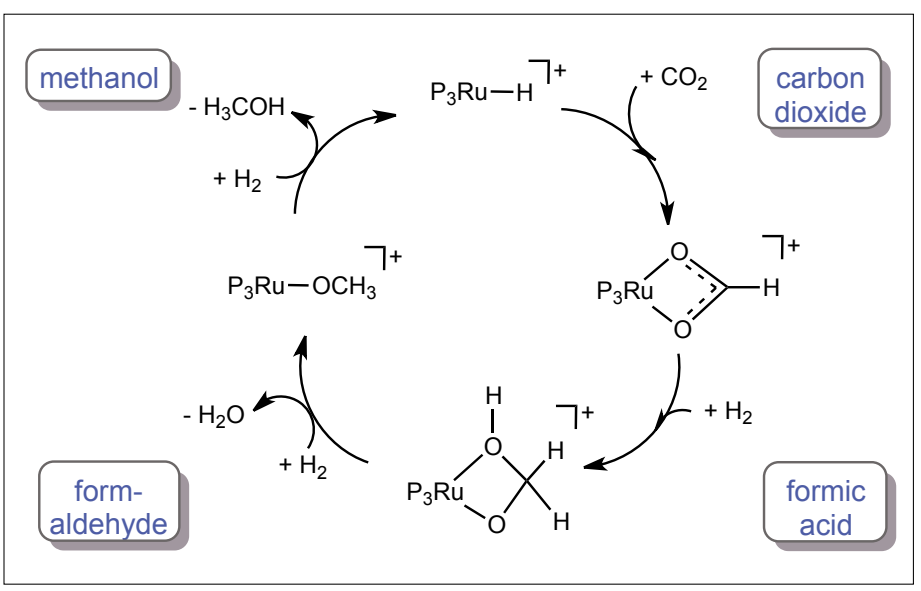

Scheme 19.

Simplified catalytic cycle for the reduction of $\mathrm{CO}_{2}$ to methanol via formic acid and formaldehyde.[33]

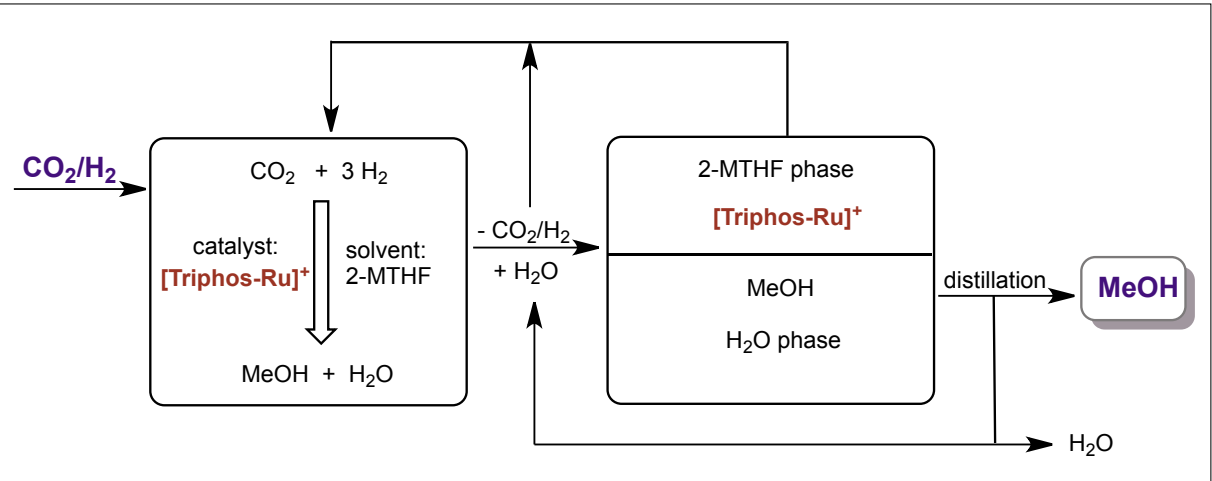

Scheme 20. Recycling of the $\mathrm{Ru}$-triphos catalyst in $\mathrm{CO}_{2}$ reduction to $\mathrm{MeOH}$ using 2-MTHF/ $\mathrm{H}_{2} \mathrm{O}$.[33]

\section{Conclusions}

Nowadays, global society needs and economical growth are still dependent on petrochemicals and fossil fuels. Thus, the sustainable production of fuels and chemicals is a topic of great interest.

The use of carbon dioxide as $\mathrm{C} 1$ building block has recently attracted interest both for the production of fuels or hydrogen rich molecules (i.e. $\mathrm{CO}_{2}$ hydrogenation to methanol or formic acid) and the production of important chemicals, contributing to the development of a low-carbon economy. Biomass could potentially become also an important resource for the production of biofuels, bioenergy and biomaterials since the selective de- and refunctionalization of biogenic substrates give important building blocks for the production of highvalue chemicals. Both approaches need the development of low-energy routes for activation and/or functionalization of feedstocks, which are often endowed with high chemical inertness. The development and use of highly active and selective catalysts, both homogeneous and heterogeneous, is pivotal to reach this target, as witnessed by the large interest of many research groups in academia and industry around the world.

Among homogeneous catalysts, recently the systems based on ruthenium and the tridentate phosphine triphos, initially known as a good catalyst for hydrogenation of esters, amides, and carboxylic acids, found a new life and use in reactions of new interest including $\mathrm{CO}_{2}$ and biomass functionalization, showing promising catalytic activity and flexibility. A subtle choice of ancillary ligands is often needed to achieve active and versatile $\mathrm{Ru}$ triphos based molecular platforms. A good example is the choice of TMM (trimethylenemethane) as in complex [Ru(triphos) (TMM)] which found various applications as summarized above.

Received: April 16, 2015

[1] P. Sevillano, A. Habtemariam, A. M. Castiñeiras, E. Garcia, P. J. Sadler, Polyhedron 1999, 18, 383.

[2] C. Bianchini, A. Meli, M. Peruzzini, F. Vizza, P. Frediani, Organometallics 1990, 9, 226.

[3] P. Barbaro, C. Bianchini, A. Meli, M. Moreno, F. Vizza, Organometallics 2002, 21, 1430.

[4] a) C. Bianchini, A. Meli, F. Vizza, J. Organomet. Chem. 2004, 689, 4277; b) C. Bianchini, A Meli, S. Moneti, F. Vizza, Organometallics 1998, 17, 2636; c) C. Bianchini, D. Masi, A. Meli, M. Peruzzini, F. Vizza, F. Zanobini, Organometallics 1998, 17, 2495.

[5] P. Barbaro, C. Bianchini, P. Frediani, A. Meli, F. Vizza, Inorg. Chem. 1992, 31, 1523.

[6] C. Bianchini, A. Meli, S. Moneti, W. Oberhauser, F. Vizza, V. Herrera, A. Fuentes, R. A. Sanchez-Delgado, J. Am. Chem. Soc. 1999, 121, 7071.

[7] C. Bianchini, A. Meli, M. Peruzzini, F. Vizza, F. Zanobini, Coord. Chem. Rev. 1992, 120, 193. 
[8] N. V. Belkova, E. V. Bakhmutova, E. S. Shubina, C. Bianchini, M. Peruzzini, V. I. Bakhmutov, L. M. Epstein, Eur. J. Inorg. Chem. 2000, 2163.

[9] a) M. C. Van Engelen, H. T. Teunissen, J. G. de Vries, C. J. J. Elsevier, Mol. Catal. A: Chem. 2003, 206, 185; b) H. Mehdi, V. Fabos, R. Tuba, A. Bodor, L. T. Mika, I. T. Horvath, Top. Catal. 2008, 48, 49; c) T. Ohkuma, R. Noyori, in 'Handbook of Homogeneous Hydrogenation', Eds. J. G. de Vries, C. J. Elsevier, John Wiley \& Sons, Weinheim, Germany, 2007; vol. 4, p. 1105; d) H. T. Teunissen, C. J. Elsevier, Chem. Commun. 1997, 667; e) H. T. Teunissen, C. J. Elsevier, Chem. Commun. 1998, 1367; f) G. R. Eastham, D. J. Cole-Hamilton, Chem. Commun. 2007, 3154; g) L. Rosi, M. Frediani, P. Frediani, J. Organomet. Chem. 2010, 695, 1314.

[10] A. B. Chaplin, P. J. Dyson, Inorg. Chem. 2008, 47,381 .

[11] a) A. Corma, S. Iborra, A. Velty, Chem. Rev. 2007, 107, 2411; b) M. Shiramizu, F. D. Toste, Angew. Chem., Int. Ed. 2012, 51, 8082; c) F. M. A. Geilen, T. vom Stein, B. Engendahl, S. Winterle, M. A. Liauw, J. Klankermayer, W. Leitner, Angew. Chem., Int. Ed. 2011, 50, 6831.

[12] a) M. Cokoja, C. Bruckmeier, B. Rieger, W. A. Herrmann, F. E. Kühn, Angew. Chem., Int. Ed. 2011, 50, 8510; b) M. Peters, B. Köhler, W. Kuckshinrichs, W. Leitner, P. Markewitz, T. E. Müller, ChemSusChem. 2011, 4, 1216.

[13] a) A. J. Ragauskas, C. K. Williams, B. H. Davison, G. Britovsek, J. Cairney, C. A. Eckert, W. J. Frederick, J. P. Hallett, D. J. Leak, C. L. Liotta, J. R. Mielenz, R. Murphy, R. Templer, T. Tschaplinski, Science 2006, 311, 484; b) A. Corma, S. Iborra, A. Velty, Chem. Rev. 2007, 107, 2411; c) G. W. Huber, S. Iborra, A. Corma, Chem. Rev. 2006, 106, 4044; d) 'Top ValueAdded Chemicals from Biomass -Results of
Screening for Potential Candidates from Sugars and Synthesis Gas', Eds. T. Werpy, G. Petersen, U.S. Department of Energy, Washington, DC, 2004, vol. 1; e) J. J. Bozell, G. R. Petersen, Green Chem. 2010, 12, 539.

[14] F. M. A. Geilen, B. Engendahl, A. Harwardt, W. Marquardt, J. Klankermayer, W. Leitner, Angew. Chem., Int. Ed. 2010, 49, 5510

[15] F. M. A. Geilen, B. Engendahl, M. Hölscher, J. Klankermayer, W. Leitner, J. Am.Chem. Soc. 2011, 133, 14349.

[16] T. vom Stein, T. Weigand, C. Merkens, J. Klankermayer, W. Leitner, ChemCatChem 2013, 5, 439.

[17] A. D. Chowdhury, R. Jackstell, M. Beller, ChemCatChem 2014, 6, 3360 .

[18] K. Eller, E. Henkes, R. Rossbacher, H. Hoke, 'Ullman's Encyclopedia of Industrial Chemistry', John Wiley \& Sons, Weinheim, 2000.

[19] D. J. C. Constable, P. J. Dunn, J. D. Hayler, G. R. Humphrey, J. L. Leazer, Jr. , R. J. Linderman, K. Lorenz, J. Manley, B. A. Pearlman, A. Wells, A. Zaks, T. Y. Zhang, Green Chem. 2007, 9, 411.

[20] M. Kliner, D. V. Tyers, S. P. Crabtree, M. A. Wood, World Patent, WO03/093208A1, 2003.

[21] J. Coetzee, D. L. Dodds, J. Klankermayer, S. Brosinski, W. Leitner, A. M. Z. Slawin, D. J. Cole-Hamilton, Chem. Eur. J. 2013, 19, 11039.

[22] T. vom Stein, M. Meuresch, D. Limper, M. Schmitz, M. Hölscher, J. Coetzee, D. J. ColeHamilton, J. Klankermayer, W. Leitner, J. Am. Chem. Soc. 2014, 136, 13217.

[23] a) 'Modern Amination Methods', Ed. A. Ricci, John Wiley \& Sons, Weinheim, 2000; b) R. N. Salvatore, C. H. Yoon, K. W. Jung, Tetrahedron 2001, 57, 7785 .
[24] a) H. T. Clarke, H. B. Gillespie, S. Z. Weisshaus, J. Am. Chem. Soc. 1933, 55, 4571; b) P. Tundo, M. Selva, Acc. Chem. Res. 2002, 35, 706.

[25] Y. Li, I. Sorribes, T. Yan, K. Junge, M. Beller, Angew. Chem., Int. Ed. 2013, 52, 12156.

[26] K. Beydoun, G. Ghattas, K. Thenert, J. Klankermayer, W. Leitner, Angew. Chem., Int. Ed. 2014, 53, 11010 .

[27] S. Savourey, G. Lefèvre, J.-C. Berthet, T. Cantat, Chem. Commun. 2014, 50, 14033.

[28] I. Mellone, M. Peruzzini, L. Rosi, D. Mellmann, H. Junge, H. Beller, L. Gonsalvi, Dalton Trans. 2013, 42, 2495.

[29] G. Manca, I. Mellone, F. Bertini, M. Peruzzini, L. Rosi, D. Mellman, H. Junge, M. Beller, A. Ienco, L. Gonsalvi, Organometallics 2013, 32, 7053.

[30] S. Savourey, G. Lefèvre, J.-C. Berthet, P. Thuéry, C. Genre, T. Cantat, Angew. Chem., Int. Ed. 2014, 53, 10466.

[31] a) A. Goeppert, M. Czaun, G. K. S. Prakash, G. A. Olah, Energy Environ. Sci. 2012, 5, 7833; b) M. Bertau, H. Offermanns, L. Plass, F. Schmidt, H.-J. Wernicke in 'Methanol: The Basic Chemical and Energy Feedstock of the Future', Springer, Berlin/Heidelberg, 2014; c) W. Wang, S. P. Wang, X. B. Ma, J. L. Gong, Chem. Soc. Rev. 2011, 40, 3703.

[32] G. Olah, A. Goeppert, G. K. Surya Prakash in 'Beyond Oil and Gas: The Methanol Economy', John Wiley \& Sons, Weinheim, 2009.

[33] a) S. Wesselbaum, T. vom Stein, J. Klankermayer, W. Leitner, Angew. Chem., Int. Ed. 2012, 51, 7499; b) S. Wesselbaum, V. Moha, M. Meuresch, S. Brosinski, K. M. Thenert, J. Kothe, T. vom Stein, U. Englert, M. Hölscher, J. Klankermayer, W. Leitner, Chem. Sci. 2015, 6, 693. 